Western North American Naturalist 68(3), (C) 2008, pp. 303-310

\title{
EFFICIENCY OF VARIOUS METHODS USED TO DETECT PRESENCE OF PYGMY RABBITS IN SUMMER
}

\author{
Eveline S. Larrucea ${ }^{1,2}$ and Peter F. Brussard ${ }^{1}$
}

\begin{abstract}
We compared pellet, burrow, visual, and camera surveys to identify a method with high efficiency for detecting current pygmy rabbit (Brachylagus idahoensis) presence at a site in summer. We used 20 known occupied sites in 4 regions of northern Nevada and eastern California for the comparison. All leporid species that occurred in the region were distinguishable in photographs, and camera surveys had a $95 \%$ detection efficiency for pygmy rabbits. Burrows were detected at $85 \%$ of total sites; however, burrows that appeared active were found at only $55 \%$ of total sites. Pygmy rabbit pellets were found at all sites, but fresh pellets were observed at only $70 \%$ of the sites. Sighting surveys detected pygmy rabbits $30 \%$ of the time. Only camera and visual surveys provided conclusive evidence of current presence. Of these methods, camera surveys were more efficient because they allowed for a longer period of detection. We also evaluated the use of road transects to detect and determine relative abundances of rabbit species in an area. Road transects detected pygmy rabbit presence in 6 of 10 transects. Relative abundance among species was biased against pygmy rabbits because of the dense vegetation they prefer to live in, their limited home ranges, and other behavioral characteristics.
\end{abstract}

Key words: pygmy rabbit, Brachylagus idahoensis, survey, camera, pellets, burrow, transect, Nevada, Great Basin, jackrabbit, cottontail.

Pygmy rabbits (Brachylagus idahoensis) are habitat specialists strictly limited to sagebrush communities in Montana, Idaho, Utah, Nevada, Oregon, Wyoming, California, and an isolated portion of Washington (Hall 1946, Gabler 1997, Heady et al. 2001). Big sagebrush (Artemisia tridentata) accounts for the majority of their diet year-round (Green and Flinders 1980), and they require dense canopy cover for protection from predators (Merriam 1891). Pygmy rabbits also are one of only 2 rabbit species in North America that dig their own burrows (Orr 1940). For these reasons, the species has a patchy distribution and occurs only in dense big sagebrush growing on deep, friable soils (Weiss and Verts 1984).

While the general habitat requirements of pygmy rabbits are well described (Weiss and Verts 1984), it also has been documented that pygmy rabbits are difficult to detect and are not found in all areas that have seemingly appropriate habitat (Janson 1946, Bradfield 1975). Pygmy rabbits generally have small home ranges of $<1$ ha that center on their burrows (Gahr 1993). They are small, inconspicuous, and elusive, and they can be easily overlooked, even when they live along a well-used trail (Grinnell et al. 1930).
With ongoing human-caused fragmentation and degradation of sagebrush communities, pygmy rabbit populations are becoming increasingly susceptible to extirpation. Sagebrush communities are being reduced and degraded by improper grazing practices, urbanization, invasive annual grasses, wildfires, and pinyonjuniper encroachment, as well as by a number of other factors (Knick and Rotenberry 2001). Due to a decline in pygmy rabbit populations in Oregon and Washington and a general lack of information about their status elsewhere, a petition was filed in 2003 to list the species as threatened or endangered under the U.S. Endangered Species Act (Fite et al. 2003). In 2005 it was concluded that insufficient data were available to assess the current distribution of the species (Federal Register 2005). Consequently, there is a need to find an accurate, reliable method to detect pygmy rabbits.

Previous methods used to detect pygmy rabbit presence have included burrow counts (McAllister 1995), pellet surveys (Rauscher 1997), and visual observations (Bradfield 1975). These methods may not always detect pygmy rabbits and may sometimes provide false identifications. Pygmy rabbit pellets can be confused with pellets of juvenile cottontails or

${ }^{1}$ Department of Biology, Program in Ecology, Evolution and Conservation Biology, University of Nevada, Reno, NV 89557.

2E-mail: esequin@unr.nevada.edu 


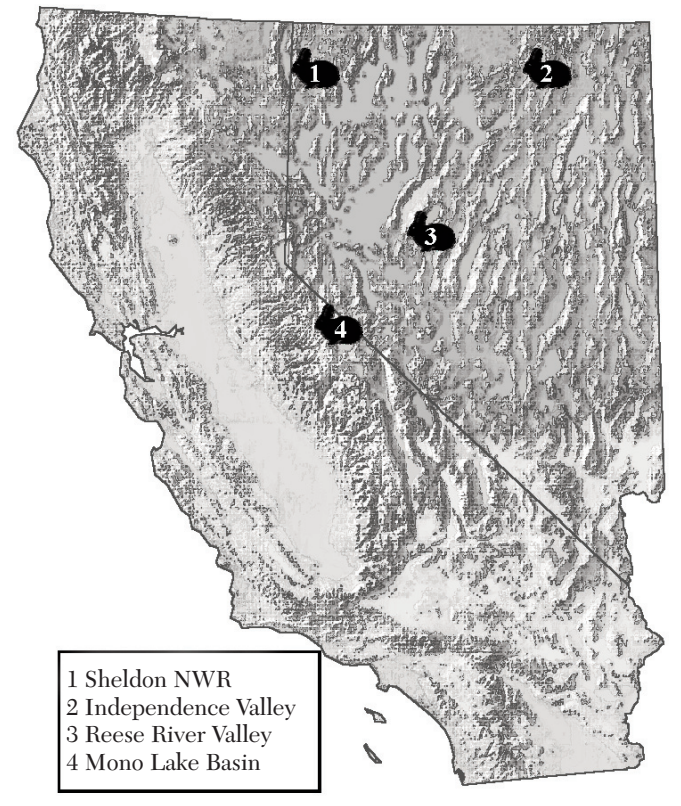

Fig. 1. Locations of pygmy rabbit surveys in 4 regions of northern Nevada and eastern California, July-October 2004.

jackrabbits, and burrows can be used by many different species. Brief sightings of rabbits by inexperienced observers also can be hard to confirm. Infrared-triggered camera systems have become an increasingly popular method of detection for elusive and/or rare animals (Cutler and Swann 1999). Road transects also are a commonly used technique for lagomorph surveys (Palomares 2001, Ballinger and Morgan 2002). We evaluated pellet, sighting, burrow, and camera survey methods at 20 sites where pygmy rabbits were known to be present. We also assessed the use of road transects to detect pygmy rabbits and determine their relative abundances in an area. Our intention was to establish an objective method with a high detection efficiency that could be used to determine the presence of pygmy rabbits at a site.

\section{Methods}

\section{Study Area}

We conducted surveys for pygmy rabbits in 4 regions of northern Nevada and eastern California. These included Independence Valley north of Elko, Elko County, Nevada; Sheldon National Wildlife Refuge (SNWR), Washoe and Humboldt counties, Nevada; Mono Lake Basin, Mono County, California; and the Reese River Valley west of Austin, Lander and Nye counties, Nevada (Fig. 1).

\section{Survey comparisons}

We compared pellet, burrow, sighting, and camera surveys at 20 sites (5 sites in each region) where pygmy rabbits were known to occur. We obtained these localities from other studies and other researchers before the start of our study. The 5 survey sites in each region were separated from each other by at least 10 $\mathrm{km}$. Pygmy rabbits generally have small home ranges of $<1$ ha (Gahr 1993). While it is unknown if the sites used included separate populations, the distance between sites ensured that surveys for pygmy rabbit sign did not overlap.

All surveys were conducted by the senior author, who was familiar with pygmy rabbit sign before the onset of the study. To maximize the probability of seeing a rabbit, we visited each site at sunrise (Bradfield 1975). At each site, we walked directly to the tallest, densest area of sagebrush, which is where pygmy rabbits are most likely to be found (Larrucea and Brussard 2008). These areas can be seen from a distance and stand out as "islands" that are taller than surrounding sagebrush (Ulmschneider 2004). We used the UTM coordinates for this "island" as the plot identifier. We surveyed the area by slowly walking through it, concentrating on the densest areas of sagebrush. We spent 1 hour at each site searching for rabbits, burrows, and pellets. Surveyed areas were generally about 2 ha in size but varied due to the amount of habitat. We recorded the locations and times of pygmy rabbit sightings using a handheld GPS unit.

We classified burrows as active (clean entrances with signs of use) or inactive (cobwebs, leaves in entrances, or collapsed; Ulmschneider 2004). We considered pellets ranging in size from 4 to $6 \mathrm{~mm}$ and occurring in aggregations under sagebrush to be pygmy rabbit sign. Adult cottontails and jackrabbits have larger pellets and distribute them more randomly (Ulmschneider 2004). While there is some overlap in the size of pellets of juvenile cottontails, juvenile jackrabbits, and pygmy rabbits, the timing of our surveys in late summer and fall reduced the likelihood that juvenile pellets were present (Larrucea 2007). We 
classified pygmy rabbit pellets as fresh (somewhat moist to the touch, not crumbly, and dark) or old (dry, easily crumbled, and brown or gray).

At the end of each 1-hour survey, we set a Trailmaster $^{\mathrm{TM}} 1550$ active infrared-triggered camera unit at each site. These units consist of an automatic camera, an infrared transmitter, and a receiver. An infrared beam is passed between the transmitter and receiver, and every time the beam is broken the camera is triggered. We set the unit near or across burrow entrances or, if burrows had not been detected, in a central location under dense sagebrush. We placed the transmitter and receiver each on a wooden stake about 2-4 $\mathrm{m}$ apart with the infrared beam approximately $5 \mathrm{~cm}$ above ground level. We set a pulse delay of 1 , which meant that the camera would be triggered only after the infrared beam had been blocked for at least 0.5 seconds. We placed 2 strips of electrical tape across the infrared lens leaving a 1-mm slit. This narrowed the beam and allowed the camera to trigger more accurately. We set a camera delay of 2 minutes so that 1 individual was not likely to use up an entire roll of film. We covered the cords leading from the receivers to the cameras in aluminum foil and buried them to discourage rodents from gnawing on them. To test the camera equipment and label the data, the 1st photo at each site was taken of an index card noting the location of the camera and the date. Cameras were unbaited, active 24 hours a day, and left at the site for 1 week.

Pygmy rabbits have very small brown tails that make them appear almost tailless, while cottontails and jackrabbits both have very distinct tails (Hall 1946). Hence, the most distinguishing photographs are those that include the tail. Pygmy rabbits also have shorter, rounder ears than do cottontails and jackrabbits, and they have white fur in their ears whereas cottontails do not (Hall 1946). Thus, side and frontal images also are distinguishable. Unique characteristics of individual rabbits such as ear notches can establish whether some individuals are photographed multiple times.

\section{Data Analysis for Survey Comparisons}

We scored each survey method at each site with a " 1 " if pygmy rabbit sign was detected and with a " 0 " if the method did not detect pygmy rabbit presence. We based detection of a species on whether the species was present at the site as well as whether the species was detected at the site. In our study, we had previous knowledge that pygmy rabbits were present at all of the selected sites. Consequently, all nondetections were known to be false negatives. Therefore, we computed the detection efficiency of each method as the percentage of sites where we detected pygmy rabbits.

\section{Road Transects}

We established road transects primarily in dense sagebrush in the Reese River Valley, which was selected because there are numerous existing dirt and improved gravel roads that go through appropriate pygmy rabbit habitat. We drove a 44.2-km standard circuit along these roads. An observer riding in a motor vehicle driven at $\sim 10 \mathrm{~km} \cdot \mathrm{hr}^{-1}$, using light from the headlights, counted numbers of each lagomorph species observed. It routinely took about 5 hours to complete the circuit. We began our observations alternately at sunset or at 3 hours before sunrise. Times of sunrise and sunset were obtained from astronomical charts. The order in which the circuit was driven also was rotated. Counts were made on 10 nights between 27 June and 31 July 2004. All counts were conducted by the same observer.

In addition to the 5 camera units set in the Reese River Valley for the survey comparisons, we set cameras at 52 additional locations in the valley in dense sagebrush between July and October 2004. Although the vegetation type at these sites was that preferred by pygmy rabbits, it was not previously known if pygmy rabbits occurred at these sites. Cameras were active for 1 week at each site. We used photographic data from these sites to look at the proportion of photographs of different lagomorphs. We compared data from the photographs to data from the road transect counts using chi-square tests of association (Quinn and Keough 2002).

\section{Results}

\section{Survey Comparisons}

The 3 lagomorph species that occurred at our study sites were black-tailed jackrabbits (Lepus californicus), pygmy rabbits, and mountain cottontails (Sylvilagus nuttallii). These were easily distinguished in photographs collected 

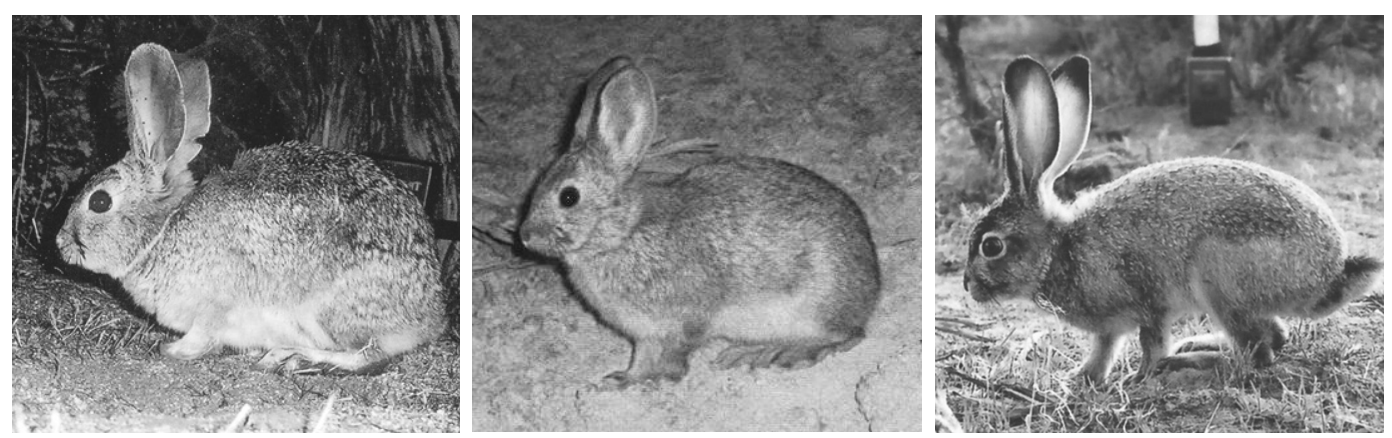

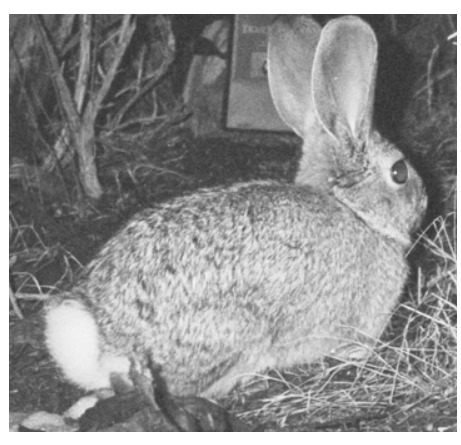

Mountain cottontail

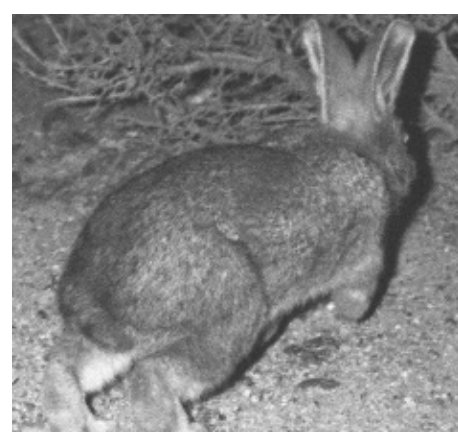

Pygmy rabbit

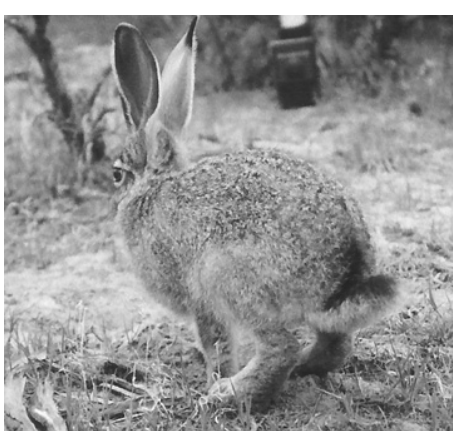

Black-tailed jackrabbit

Fig. 2. Lagomorph species photo-captured during camera surveys in northern Nevada and eastern California, July-October 2004. Pygmy rabbits were identifiable from their shorter, rounder ears lined with white fur, as well as their distinctive small brown tail. Other useful characteristics distinguishing pygmy rabbits were generally darker feet than mountain cottontails. Black-tailed jackrabbits were distinguishable from cottontail and pygmy rabbits by their long limbs and dark markings on ears, tail, and face.

with infrared-triggered cameras (Fig. 2). Certain distinguishable individuals were photographed multiple times during the week.

Between 23 July and 3 October 2004, we conducted sighting, burrow, pellet, and camera surveys at the 20 selected sites known to have pygmy rabbits (Table 1 ). We detected burrows at $85 \%$ of the sites; however, we found active burrows at only $55 \%$ of them. We found pygmy rabbit pellets at all sites but found fresh pellets at only $70 \%$ of sites. Sighting and camera surveys detected pygmy rabbits $30 \%$ and $95 \%$ of the time, respectively. Pygmy rabbits were seen only at sites where fresh pellets were found, but they were photographed at all but 1 site (Table 1). At the 1 site with no photo-capture, pygmy rabbits were confirmed to be present in a subsequent week of photo-surveying. Hence, we photographed pygmy rabbits at $100 \%$ of the sites, although 1 site required 2 weeks of photo-surveying. Pygmy rabbits were photographed at all types of active sites in- cluding those where only old pellets and inactive-looking burrows were found. Because the presence of old pellets at a site does not confirm current presence of pygmy rabbits, camera surveys were the most effective method to detect current presence of pygmy rabbits at a site (Table 1).

\section{Road Transects}

We observed 569 lagomorphs on the 10 road-transect counts and identified 545 to species (Table 2). Black-tailed jackrabbits composed $90.1 \%(n=491)$, mountain cottontails $8.1 \%(n=44)$, and pygmy rabbits $1.8 \%(n=$ 10) of all leporids observed on road transects. Data from the 52 camera locations placed in the Reese River Valley for July-October 2004, as well as the 5 stations for the survey, provided 409 lagomorph photographs. Black-tailed jackrabbits comprised $48.7 \%(n=199)$ of the photographs, pygmy rabbits $47.7 \%(n=195)$, and mountain cottontails $3.7 \%(n=15)$. The 
TABLE 1. Presence of pygmy rabbits at 20 sites as detected with sighting, burrow, pellet, and camera techniques in northern Nevada and eastern California, July-October 2004. A site was labeled with a "1" if the method detected pygmy rabbits and a " 0 " if rabbits were not detected.

\begin{tabular}{|c|c|c|c|c|}
\hline Region and sample \# & Sighting & Burrow $^{a}$ & Pellet $^{\mathrm{b}}$ & Camera $^{\mathrm{c}}$ \\
\hline \multicolumn{5}{|l|}{ Reese River Valley } \\
\hline 1 & 0 & $1 \mathrm{~A}$ & $1 \mathrm{~F}$ & $1(3)$ \\
\hline 2 & 1 & $1 \mathrm{~A}$ & $1 \mathrm{~F}$ & $1(7)$ \\
\hline 3 & 1 & $0-$ & $1 \mathrm{~F}$ & $1(14)$ \\
\hline 4 & 1 & $1 \mathrm{I}$ & $1 \mathrm{~F}$ & $1(9)$ \\
\hline 5 & 0 & $1 \mathrm{~A}$ & $1 \mathrm{~F}$ & $1(5)$ \\
\hline \multicolumn{5}{|l|}{ Independence Valley } \\
\hline 1 & 0 & $1 \mathrm{~A}$ & $1 \mathrm{~F}$ & $1(2)$ \\
\hline 2 & 0 & $1 \mathrm{I}$ & 10 & $0(0)$ \\
\hline 3 & 0 & $1 \mathrm{I}$ & 10 & $1(8)$ \\
\hline 4 & 0 & $1 \mathrm{~A}$ & $1 \mathrm{~F}$ & $1(9)$ \\
\hline 5 & 0 & $1 \mathrm{~A}$ & 10 & $1(4)$ \\
\hline \multicolumn{5}{|l|}{ Sheldon NWR } \\
\hline 1 & 0 & $1 \mathrm{~A}$ & $1 \mathrm{~F}$ & $1(9)$ \\
\hline 2 & 0 & $1 \mathrm{~A}$ & $1 \mathrm{~F}$ & $1(13)$ \\
\hline 3 & 1 & $0-$ & $1 \mathrm{~F}$ & $1(9)$ \\
\hline 4 & 0 & $1 \mathrm{I}$ & 10 & $1(6)$ \\
\hline 5 & 0 & $0-$ & $1 \mathrm{~F}$ & $1(11)$ \\
\hline \multicolumn{5}{|l|}{ Mono Lake Basin } \\
\hline 1 & 0 & $1 \mathrm{I}$ & $1 \mathrm{~F}$ & $1(5)$ \\
\hline 2 & 1 & $1 \mathrm{I}$ & $1 \mathrm{~F}$ & $1(8)$ \\
\hline 3 & 1 & $1 \mathrm{~A}$ & $1 \mathrm{~F}$ & $1(12)$ \\
\hline 4 & 0 & $1 \mathrm{~A}$ & 10 & $1(6)$ \\
\hline 5 & 0 & $1 \mathrm{~A}$ & 10 & $1(4)$ \\
\hline PERCENT CORRECT & $30 \%$ & $\begin{array}{c}85 \% \\
(55 \% \mathrm{~A})\end{array}$ & $\begin{array}{c}100 \% \\
(70 \% \mathrm{~F})\end{array}$ & $95 \%$ \\
\hline
\end{tabular}

a Burrows were classified as either active (A) or inactive (I).

bPellets were classified as either fresh $(\mathrm{F})$ or old $(\mathrm{O})$.

${ }^{\mathrm{c}}$ Number of pygmy rabbit photographs obtained in 1 week.

TABLE 2. Numbers of lagomorphs identified in road transects conducted in the Reese River Valley, Nevada, June-July 2004. Transects were initiated at sunset (PM) or at 3 hours before sunrise (AM).

\begin{tabular}{lccc}
\hline & \multicolumn{3}{c}{ Numbers observed } \\
\cline { 2 - 4 } Transect & Jackrabbit & Cottontail & Pygmy rabbit \\
\hline $6 / 27 / 04(\mathrm{PM})$ & 87 & 6 & 1 \\
$6 / 30 / 04(\mathrm{AM})$ & 28 & 1 & 0 \\
$7 / 02 / 04(\mathrm{AM})$ & 55 & 5 & 2 \\
$7 / 08 / 04(\mathrm{PM})$ & 48 & 2 & 0 \\
$7 / 12 / 04(\mathrm{AM})$ & 87 & 9 & 3 \\
$7 / 14 / 04(\mathrm{PM})$ & 46 & 8 & 2 \\
$7 / 23 / 04(\mathrm{PM})$ & 36 & 1 & 0 \\
$7 / 27 / 04(\mathrm{AM})$ & 17 & 3 & 1 \\
$7 / 29 / 04(\mathrm{AM})$ & 44 & 6 & 1 \\
$7 / 31 / 04(\mathrm{PM})$ & 43 & 3 & 0 \\
Total & 491 & 44 & 10 \\
\% of total & $90.1 \%$ & $8.1 \%$ & $1.8 \%$ \\
\hline
\end{tabular}

proportion of jackrabbits and cottontails was not significantly different between the roadtransect counts and those recorded in the photographs $\left(\chi^{2}{ }_{1}=0.17, P=0.680\right)$. However, when pygmy rabbits were included in the analysis, there was a highly significant association between the technique used and the proportion of each species detected $\left(\chi^{2}{ }_{1}=299.31\right.$, $P<0.001)$ because of the extreme under-representation of pygmy rabbits in the road-transect surveys.

\section{Discussion}

\section{Survey Comparisons}

The detection of a species at a site is based on whether it is present at the site and whether it is detected (MacKenzie 2005). We accounted for uncertainty in the presence of pygmy rabbits by surveying sites that were known to be occupied. Although we did not estimate detection probabilities for each survey technique, we provide useful information about the detection efficiency of sighting, pellet, burrow, camera, and road survey techniques to detect presence of pygmy rabbits in summer.

Camera surveys were shown to be more effective in documenting current pygmy rabbit 
presence at a site than were burrow, pellet, sighting, or transect surveys. Mountain cottontails, black-tailed jackrabbits, and pygmy rabbits were relatively easy to distinguish in photographs, and, with some practice, pygmy rabbits could be identified from photographs very quickly. Certain individuals were identifiable by distinct notches in their ears, and these rabbits generally were photographed several times at a site over the course of the week. Rabbits did not tend to leave an area due to the equipment, and if any 1 photo was inconclusive, a 2nd photo of the individual often was available to provide conclusive identification.

Though burrows are a good initial indicator that pygmy rabbits may be present, finding a burrow does not necessarily mean that the species is currently at the site. In certain environments, burrows may remain visible for many years after rabbits have vacated a site (Janson 2002); therefore, most burrow surveys use only active burrows as an indication of pygmy rabbit presence. However, even burrows that appear active may not currently be used by pygmy rabbits. Cameras captured a number of other species using burrows, including black-tailed jackrabbits, chipmunks (Neotamias minimus), kangaroo rats (Dipodomys sp.), and badgers (Taxidea taxus). If current pygmy rabbit activity is unknown at a site, a burrow appearing to be active cannot be used as evidence of current presence.

Conversely, a lack of active burrows may not necessarily indicate a lack of pygmy rabbits. Studies have noted that during certain seasons pygmy rabbits may not use burrows (Janson 1946, Katzner 1994, Larrucea 2007). Some pygmy rabbits may use forms (small indentations in the soil) during the warm summer months, and cobwebs and vegetation quickly can make a burrow look unused. Burrows that appear inactive during summer may be used again during winter months or in following years by pygmy rabbits (Larrucea 2007). Burrows also may be small, hidden, and difficult to find. In our surveys we were unable to find burrows at 3 active sites in an hour. Also, burrows may not be located in areas that pygmy rabbits use only for dispersal. We have photographic, pellet, and sighting evidence of pygmy rabbits in a valley in northern Nevada where no burrows have been detected (E.S. Larrucea personal observation).
A final problem with using burrow surveys exclusively is that desert cottontails (Sylvilagus auduboni) also make burrows (Orr 1940) and may deposit pellets similar to those of pygmy rabbits. In areas where the distributions of these 2 species overlap (such as in southeastern Nevada), burrow surveys without photographic or visual evidence may be inadequate in determining current pygmy rabbit presence (e.g., Himes and Drohan 2007).

We detected old pygmy rabbit pellets at every site. However, pellets can remain for more than 1 year (Flinders and Crawford 1977) and do not necessarily provide evidence that pygmy rabbits currently are present at sites. When we used only fresh pellets, detection efficiency dropped to 70\%. Another problem with using only pellet surveys is that pygmy rabbits coexist with both jackrabbits and cottontails (Heady 1998). While there are significant differences in pellet sizes among adult rabbits, pellets from young rabbits may be misidentified. This is especially true in spring when many juvenile animals are present. Pellet surveys may be most successful during seasons when few juveniles are present.

Once again, the opposite is true as well: finding no fresh-looking pygmy rabbit pellets at a site does not mean that pygmy rabbits are not currently present. Different environmental conditions can change the rate that pellets dry and change color (Flinders and Crawford 1977).

Finally, like camera surveys, sighting surveys provide conclusive evidence of current presence. However, observers should be experienced with pygmy rabbit characteristics, because pygmy rabbits can easily be confused with young cottontails and young jackrabbits. The drawbacks to visual surveys are a very low detection rate due to dense vegetation and the limited home ranges and the elusive nature of the species.

\section{Road Transects}

Although transect studies have been conducted successfully for other rabbit species, a number of factors make this method of data collection inefficient for pygmy rabbits. First, pygmy rabbits live in dense sagebrush, which limits transect widths to narrow bands along roadsides. Second, pygmy rabbits are reluctant to cross open areas (Bradfield 1975) and therefore may be less likely than other rabbits to cross a road. Bradfield (1975) noted a scarcity 
of pygmy rabbits in animal highway mortality studies. Third, pygmy rabbits are more likely than cottontails and jackrabbits to remain hidden under a shrub, run a short distance and stop, or take refuge in a burrow rather than run a long distance when flushed. This attribute makes them less detectable in road transects. This means that while jackrabbits and cottontails were seen in proportion to their representation in photographs, pygmy rabbits were underrepresented in road transects.

Road transects inherently cover many miles and do not focus on the specific habitat requirements of pygmy rabbits. Therefore, road transects do not provide an effective means of conclusively determining whether pygmy rabbits are present in the transected area. However, road transects might be useful as a 1st indication of whether more intense surveys should be conducted.

\section{Conclusion}

While all survey types detected evidence of pygmy rabbits, only visual, camera, and transect surveys were able to detect current pygmy rabbit presence conclusively. Of these 3 methods, camera surveys were far more efficient because they allowed for a longer period of detection. Major drawbacks of camera surveys are that cameras are expensive and surveys can be limited by the number of cameras available. Using cameras also requires 2 visits to a site, 1 for set-up and 1 for pickup. However, camera expenses may be offset by the need for fewer personnel. Personnel also do not have to be experienced with pygmy rabbit sign to obtain reliable results with cameras. Cameras have the added benefit of collecting additional data on other species in the area, and, unlike observations, photographs can be shown to other researchers for further confirmation. Surveyors experienced with pygmy rabbit sign can use a combination of fresh pellets and burrows as an indicator of current presence; however, a secondary method should be used to conclusively prove presence at questionable sites.

Finally, the season in which a survey is conducted is very important. We conducted surveys during late summer when our field sites were easily accessible and pellet sizes of different rabbit species were more distinct. However, in winter when snow is present, the results would be quite different. Fresh pellets are clearly visible on the surface of the snow and are known to be recent. Burrows often are cleared of snow and open to the surface. Burrow and pellet techniques would provide evidence of current presence in winter. Conversely, cameras can be triggered by large snowflakes and can become inoperable during heavy snowfall. Therefore, the detection efficiencies of these methods change under different climatic conditions.

\section{Literature Cited}

Ballinger, A., AND D.G. Morgan. 2002. Validating two methods for monitoring population size of the European rabbit (Oryctolagus cuniculus). Wildlife Research 29:431-437.

BRADFIELD, T. 1975. On the behavior and ecology of the pygmy rabbit (Sylvilagus idahoensis). Master's thesis, Idaho State University, Pocatello.

CutLer, T.L., AND D.E. SWANn. 1999. Using remote photography in wildlife ecology: a review. Wildlife Society Bulletin 27:571-581.

Federal Register. 2005. Endangered and threatened wildlife and plants; 90-day finding on a petition to list the pygmy rabbit as threatened or endangered. Federal Register 70:29253-29265.

Fite, K., J. Marvel, M. Salvo, B. Marlette, J. Kessler, J. SMITH, AND C. CRidDLE. 2003. A petition for rules to list the pygmy rabbit Brachylagus idahoensis occurring in the coterminous Intermountain and Great Basin region as threatened or endangered under the Endangered Species Act 16 USC 1531 seq. U.S. Fish and Wildlife Service, Committee for the High Desert, Boise, ID. 216 pp.

Flinders, J.T., AND J.A. Crawford. 1977. Composition and degradation of jackrabbit and cottontail fecal pellets, Texas High Plains. Journal of Range Management 30:217-220.

GableR, K.I. 1997. Distribution and habitat requirements of the pygmy rabbit on the Idaho National Environmental and Engineering Laboratory. Master's thesis, Department of Biology, Idaho State University, Pocatello.

GAHR, M.L. 1993. Natural history, burrow and habitat use, and home range of the pygmy rabbit (Brachylagus idahoensis) of sagebrush flat, Washington. Master's thesis, University of Washington, Seattle.

GreEn, J.S., AND J.T. Flinders. 1980. Habitat and dietary relationships of the pygmy rabbit. Journal of Range Management 33:136-142.

Grinnell, J., J. Dixon, and J.M. Linsdale. 1930. Vertebrate natural history of a section of northern California through the Lassen Peak region. University of California Publications in Zoology 35:553-562.

HaLL, E.R. 1946. Mammals of Nevada. University of California Press, Berkeley.

HEADY, L.T. 1998. Home range, habitat, and activity patterns of pygmy rabbits (Brachylagus idahoensis) in southeast Idaho. Master's thesis. Idaho State University, Pocatello. $72 \mathrm{pp}$.

Heady, L.T., K.I. Gabler, AND J.W. LaundRe. 2001. Habitat selection by pygmy rabbits in southeast Idaho. BLM Technical Bulletin No. 01-7. 
Himes, J.G., and P.J. Drohan. 2007. Distribution and habitat selection of the pygmy rabbit (Brachylagus idahoensis) in Nevada. Journal of Arid Environments 68:371-382.

Janson, R.G. 1946. A survey of the rabbits of Utah with reference to their classification, distribution, life histories and ecology. Master's thesis, Utah State Agricultural College, Logan.

2002. The pygmy rabbit from Utah to Montana

University of Montana. Cooperative Wildlife Research Unit. Missoula, MT.

KATZNER, T.E. 1994. Winter ecology of the pygmy rabbit in Wyoming. Master's thesis, University of Wyoming, Laramie. 124 pp.

Knick, S.T., And J.T. RotenberRy. 2001. Ghosts of habitats past: contribution of landscape change to current habitats used by shrubland birds. Ecology 81:220 227.

LARRUCEA, E.S. 2007. Distribution, behavior and habitat preferences of the pygmy rabbit (Brachylagus idahoensis) in Nevada and California. Doctoral dissertation, University of Nevada, Reno.

Larrucea, E.S., and P.F. Brussard. 2008. Habitat selection and current distribution of the pygmy rabbit in Nevada and California, USA. Journal of Mammalogy 89:691-699.

MacKenzIE, D.I. 2005. What are the issues with presence/absence data for wildlife managers? Journal of Wildlife Management 69:849-860.
MCAlLister, K.R. 1995. Washington State recovery plan for the pygmy rabbit. Washington Department of Fish and Wildlife, Olympia. 73 pp.

Merriam, C.H. 1891. Results of a biological reconnaissance of south-central Idaho. North American Fauna 5:1-416.

ORR, R.T. 1940. The rabbits of California. Occasional Papers of the California Academy of Sciences 19: $1-227$.

Palomares, F. 2001. Comparison of three methods to estimate rabbit abundance in a Mediterranean environment. Wildlife Society Bulletin 29:578-585.

Quinn, P.G., AND M.J. KeOugh. 2002. Experimental design and data analysis for biologists. Cambridge University Press, Cambridge, U.K. 520 pp.

Rauscher, R.L. 1997. Status and distribution of the pygmy rabbit in Montana. MFWP Report, WDFW, Bozeman, MT. 19 pp.

Ulmschneider, H. 2004. Surveying for pygmy rabbits (Brachylagus idahoensis). BLM Technical Report, 4th draft, 3 June 2004.

WEISS, N.T., AND B.J. VERTs. 1984. Habitat and distribution of pygmy rabbits in Oregon. Great Basin Naturalist 22:563-571.

Received 10 May 2007

Accepted 7 February 2008 